\title{
Amnesia following the rupture and repair of an anterior communicating artery aneurysm
}

\author{
BRUCE T VOLPE, ${ }^{*}$ WILLIAM HIRST $\dagger$ \\ From the Cornell University Medical College, Department of Neurology, ${ }^{*}$ New York and Princeton \\ University, $\dagger$ Department of Psychology, Princeton, New Jersey, USA
}

SUMMARY Clinical analysis and neuropsychological criteria derived from experimental studies of human amnesic syndromes, particularly the alcoholic Korsakoff's syndrome, have been used to characterise an unusual form of amnesia that occurred in two patients after rupture of an anterior communication cerebal artery aneurysm. Intraoperative observation and multiple CT scans did not reveal focal brain damage. Arteriography showed that both patients had arterial vasospasm. The amnesia has persisted over three years since the surgery. Study of the characteristics of their amnesia showed several features in common with other amnesic syndromes, including severely depressed free recall, and less depressed recognition of visual and verbal material. Chronic amnesic syndromes with characteristics of classical amnesic syndromes occur infrequently after rupture and repair of intracranial aneurysms, and, if not caused by parenchymal haemorrhage, may follow pre-operative vasospasm.

An amnesic syndrome follows brain injury from a number of pathophysiologic aetiologies. Whereas the amnesia associated with alcoholic Korsakoff's syndrome, ${ }^{12}$ temporal lobe resection, ${ }^{34}$ or herpes encephalitis $^{56}$ has been studied clinically and experimentally, the amnesia that follows the rupture and repair of a cerebral artery aneurysm, particularly in the anterior circulation, has not been so well described. ${ }^{7-13}$ Most studies of this amnesia suggested that the memory deficit was transient, and "Korsakoff-like" with confusion, inattentiveness and confabulation. ${ }^{10-14}$ This transient amnesia often followed frontal lobe haemorrhage or, in the course of aneurysm repair, frontal lobe removal. Other reports with extended longitudinal evaluations of patients with aneurysm rupture and repair, suggested that residual memory deficits were chronic, but these reports lacked detailed neuropsychological analysis. ${ }^{7} 1516$

To the rare reports that attempted to characterise the features of this chronic amnesic syndrome,,$^{10} 18$ we add the present study, which reports two patients with amnesia three years after they sustained a ruptured anterior communicating artery aneurysm.

Address for reprint requests: Dr BT Volpe, Cornell University Medical College, 525 E 68 Street, New York, NY 10021, USA.

Received 18 November 1982 and in revised form 11 February 1983. Accepted 27 March 1983.
They presented to surgery classified as grade $2,{ }^{19}$ without clinical signs of amnesia. They had no CT evidence or intra-operative evidence of parenchymal brain damage. However, before operation both patients had arteriographic evidence of vasospasm in the anterior cerebral artery circulation. This report attempts to characterise their chronic amnesic syndrome from the neurological and neuropsychological perspective, and with a series of experimental tests derived from the literature on the classic amnesias.

\section{Case reports}

\section{Patient 1}

A 45-year-old woman was brought to the hospital in January 1980 after three days of an excruciating bi-frontal headache. The pain was of sudden onset, and constant in the frontal and periorbital regions. There was no loss of consciousness. On initial examination she was alert and oriented. She named objects and colours, and followed commands. She repeated seven digits, and remembered three unrelated items after three minutes. She calculated without difficulty. She remembered the Presidents correctly back to Roosevelt. The remainder of the medical/ neurologic examination was normal except for a stiff neck.

A lumbar puncture revealed an opening pressure of 320 mm of $\mathrm{H}_{2} \mathrm{O}$ and was grossly bloody. A CT scan revealed increased density in the interhemispheric fissure representing blood, and a rounded enhancement anterior to the 
sella. Arteriography revealed a $7 \mathrm{~mm}$ diameter right anterior communicating aneurysm associated with spasm in the right A-1 segment that suggested recent haemorrhage. A smaller aneurysm $(5 \mathrm{~mm})$ was identified at the right middle cerebral artery bifurcation. Her condition remained stable. On the ninth hospital day, and twelve days after her initial headache symptoms, both aneurysms were clipped. Direct visualisation of both aneurysms showed that only the anterior communicating aneurysm had ruptured. One day after the operation she was alert, but disoriented and confused about surgery. The remainder of her neurological examination was normal. Ten days later, she was oriented, but failed to remember the doctors who managed her daily care. She failed to remember any of three unrelated items after three minutes. She repeated five digits. She named objects and colours, and followed commands. She could calculate without difficulty. She remembered she had an "excruciating headache ..." and an operation, but most of the events of the past several months had " . . . flitted out of (her) mind". She appeared bland and unconcerned. Because of this amnesia she had a repeat arteriogram two weeks after the operation. It showed persistent significant spasm of the right A-1 and M-1 segments of the supraclinoid carotid. There was associated decreased filling of the anterior circulation.

She was referred for further evaluation one year later, because of peristent amnesia. At that time, general medical and neurological examination was unremarkable. She was alert and oriented. She named objects and colours, and followed commands. She repeated five digits, yet she failed to remember any of three unrelated items after three minutes. She did not confabulate. She complained that, ". . . memories of recent events disappear in a flash". She remembered her birthdate and age. She recongnised one of the experimenters whom she met frequently, and she recognised one of her doctors. She remembered working as a loan clerk for a bank. She recalled remote events like the neighbourhood where she spent her childhood. She remembered certain personal events, for example, her daughter had suffered appendicitis and needed surgery. She failed to remember current events like the 1980 presidential election, and the release of the American hostages from the embassy in Iran. She had not returned to work and remained dependant on her husband. Two years after the operation, a repeat CT scan with coronal slices was normal. Surgical clips were noted at the base of the frontal lobes.

\section{Patient 2}

A 41-year-old man was admitted to hospital in January 1980 after one week of unremitting excruciating headaches. The headache began suddenly and was associated with a single two-minute episode of syncope. On initial examination he was alert and oriented. He named objects and colours, and followed commands. He repeated seven digits, and remembered three of three unrelated items after three minutes and twenty-minutes. He performed calculations accurately. His fund of knowledge and judgement was normal. The remainder of the examination was normal.

Lumbar puncture revealed an opening pressure of 180 $\mathrm{mm} \mathrm{H}_{2} \mathrm{O}$, and xanthochromic spinal fluid with many red cells. A CT scan was normal. Arteriography revealed an aneurysm of the left anterior communicating artery with spasm of the anterior circulation. He remained in a stable condition. On the fifth hospital day, some twelve days after his initial symptoms of headache and loss of consciousness, the anterior communicating artery aneurysm was clipped.

One day after surgery he was confused, disoriented, and remembered none of three items soon after presentation. He named objects and colours, and followed commands, and repeated five digits. The remainder of his neurological examination was normal. Ten days after surgery, he knew that he had been sick after a headache, and that he had had an operation, but he appeared unconcerned about the consequences of his injury. He was oriented to place and person, he knew the year but not the month or the date. He knew his address, phone number, birth date and birth place. He failed to remember any of three unrelated items after a short delay. He recalled one item from a story that was read to him from the Wechsler Memory Scale. He recognised his attending doctors, but could not remember their names. While he could not remember the details of the events that had occurred in the past few months, he remembered which schools he had attended, and his most recent job. He read, wrote and drew figures without difficulty. He calculated accurately. This pattern of memory deficits did not improve. He was discharged in the care of his wife.

He was unable to return to work because the memory deficit did not improve. He was referred to us one year later with the complaint that " . . my memory is a blank". Neurologic examination revealed a mild right supranuclear facial nerve loss, and an extensor plantar response on the right. His blood pressure was normal. He was alert and oriented, and knew his birthdate and age. He did not confabulate. He had a digit span of six numbers forward, but could not remember any of three unrelated objects after five minutes. He recognised neighbours, old friends, and one of the experimenters with whom he had frequent contact. He failed to remember any of the primary physicians who had attended to his care during his illness and surgery. He remembered some of the projects he was completing at his job in the fall of 1980 , but was "blank" from early November to the present. He recalled remote events about the neighbourhood where he had lived as a child, and courting his wife. He recalled salient personal events like the birth of his children, and decisions about his career. He had difficulty recalling current events, like the Pope's visit to New York and the political turmoil caused by the admission to a New York hospital of a former middle eastern head of state. His life consisted of participating in a rehabilitation programme near his house. He was completely dependant of his wife.

A repeat CT scan one year after operation was normal, with the exception of surgical clips at the base of the frontal lobes.

\section{NEUROPSYCHOLOGICAL EVALUATION}

The neuropsychological tests summarised in table 1 and the experimental studies occurred between 1981 and 1982. The patients' full scale average Wechsler Adult Intelligence Scale (IQ) was 115 (high average), ${ }^{20}$ and their average Wechsler Memory Scale (MQ) was 84 (low average). 
Table 1

\begin{tabular}{|c|c|c|}
\hline & Patient 1 & Patient 2 \\
\hline $\begin{array}{l}\text { WAIS } \\
\text { Full Scale } \\
\text { Digit Span } \\
\text { Wechsler Memory Scale (hard } \\
\text { paired associate learning } \\
\text { number correct) } \\
\text { Graham Kendall Memory for } \\
\text { Designs (N = normal, } \\
\text { B = borderline } \\
\text { Token Test (NE = no errors) } \\
\text { Ravens Progressive Matrix } \\
\text { (percentile) } \\
\text { Wisconsin Card Sorting, } \\
\text { categories achieved } \\
\text { (errors) }\end{array}$ & $\begin{array}{r}113 \\
5 \\
87 \\
(0)\end{array}$ & $\begin{array}{r}116 \\
6 \\
83 \\
(1)\end{array}$ \\
\hline
\end{tabular}

Their performance on the Associate Learning Task was uniformly poor: patient 1 learned none and patient 2 learned one difficult word pairs after three trials. IQ equals MQ for a normal population, and recent studies of patients with Korsakoff's amnesia have recorded IQ/MQ differences of 20 points or more. ${ }^{21}$ Differences of this degree have been thought to reflect memory impairments more severe than general intellectual dificits. ${ }^{22}$ Additional evaluation of memory included borderline performance on the Graham Kendall Memory for Design test, although they had no difficulty drawing a cube or house in perspective. ${ }^{23}$

The Wisconsin Card Sort was administered according to standard instructions. ${ }^{23}{ }^{24}$ Both patients achieved the maximum of six categories, however patient 1 made many errors $(=45)$. Patient 1 made random mistakes characterised by a difficulty in maintaining the category. There was no severe perseveration. Milner has reported that patients with temporal and parietal lesions make as many errors as patient $1 .^{24}$ Milner's patients with frontal lobe resection also made many errors, but achieved only 1-3 categories.

The Ravens Progressive Matrices is a test of nonverbal intellectual abilities. ${ }^{23}$ The scores are normalised for age. Patient 1 scored in the 50 centile on the Ravens and Patient 2 scored in the 80 centile. These scores are average or above average. Although some investigators have reported 'that average performance on the Raven's test relates to the presence of apraxia or visual field defect, neither defect was present in these patients. Investigators have also reported that Raven's scores correlate with performance in constructional tasks. In this regard both patients performed worst on the block design sub-test of the WAIS (scaled score for both $=8$ ). Finally, they did not have aphasia or agnosia, and performed perfectly on the Token test. ${ }^{25}$

\section{EXPERIMENTAL ASSESSMENT}

The experimental tests were selected on the basis of a recent review of the literature on anterograde amnesia. Investigators have suggested that amnesias associated with Korsakoff's syndrome, hypoxic ischaemic injury, and herpes encephalitis have at least five characteristics in common. ${ }^{26-28}$ They are briefly: intact short term memory, poor free recall, responsiveness to recognition probes, responsiveness to retrieval cues, increased susceptibility to interference. Patients' performance in four tasks was compared to a control group of six volunteers who were age and matched for education level. The control subjects were solicited by an advertisment in a local newspaper.

1 Assessment of free recall of visual and verbal material. In the verbal recall test, there were 15 lists of 10 words. Each work was typed on an index card and was presented for five seconds. There were equal number of high and medium frequency words, and no word was repeated. There were three conditions: immediate, 30 second delay, and five minute delay. The patient was asked to recall verbally as much as possible from the list. There were five lists in each condition, and conditions were presented in a random manner for a total of 15 blocks of trials. During the delay periods, distraction consisted of conversation with the experimenter about unrelated topics.

The procedure for the visual recall was the same as for verbal recall, except that instead of words, five sets of 10 slides of an unfamiliar area of the city were used as stimulus material. After a five minute delay period of conversation with the experimenter, the patient tried to recall in as much detail as possible what was studied. There were five trials. The free recall was tape recorded, transcribed, and scored as follows: two judges looked at the slides and made an arbitrary list of ten outstanding features in each set of ten slides. Two judges then compared lists with the recall protocols. There was perfect agreement between the judges as to when a feature appeared on the protocol.

The results in table 2 show that amnesics performed worse than controls in verbal recall in all three delay conditions, and that the amnesic performance deteriorated substantially with long delays. Visual recall was also worse than controls. The patients often failed to recall a single item from the slides they had studied (table 2).

2 Assessment of recognition of visual and verbal material The verbal recognition task had the same design as the verbal recall task, except that a recognition task followed the delay period ( 15 lists of 10 words, 3 delay conditions). Each block of trials for the recognition test consisted of 10 words from the to-be-remembered list ("old" words) and ten new words matched for word frequency. Words for the recognition test were typed on index cards and presented in random order. Subjects were asked to choose which they had seen on the previously presented list. Delay periods were the same as in the free recall experiments.

The visual recognition task followed each visual recall test. After trying to recall features of a set of ten slides,

Table 2 Free recall of verbal and visual material. Proportion correct (standard deviation)

\begin{tabular}{|c|c|c|c|c|}
\hline & \multicolumn{2}{|c|}{ Patients } & \multirow{2}{*}{\multicolumn{2}{|c|}{$\begin{array}{l}\text { Control } \\
\text { group }\end{array}$}} \\
\hline & 1 & 2 & & \\
\hline $\begin{array}{l}\text { Verbal } \\
\text { Immediate } \\
30 \text { s delay } \\
5 \text { min delay }\end{array}$ & $\begin{array}{l}0.50 \\
0.25 \\
0.10\end{array}$ & $\begin{array}{l}0.30 \\
0.24 \\
0.02\end{array}$ & $\begin{array}{l}0.56 \\
0.47 \\
0.31\end{array}$ & $\left.\begin{array}{l}(0 \cdot 15) \\
0 \cdot 12 \\
0 \cdot 14\end{array}\right)$ \\
\hline $\begin{array}{l}\text { Visual } \\
5 \text { min delay }\end{array}$ & 0.05 & 0.07 & 0.40 & $(0 \cdot 13)$ \\
\hline
\end{tabular}


Table 3 Recognition of verbal and visual material. Proportion correct (standard deviation)

\begin{tabular}{llllll}
\hline & \multicolumn{2}{l}{ Patients } & \multicolumn{3}{l}{$\begin{array}{l}\text { Control } \\
\text { group }\end{array}$} \\
\cline { 2 - 3 } & 1 & 2 & & \\
\hline Verbal & 0.86 & 0.72 & 0.73 & $(0.15)$ \\
$\quad$ Immediate & 0.50 & 0.56 & 0.69 & $(0.17)$ \\
30 s delay & 0.46 & 0.36 & 0.46 & $(0.21)$ \\
5 min delay & & & & \\
$\quad \begin{array}{llllll}\text { Visual } \\
5 \text { min delay }\end{array}$ & 0.80 & 0.86 & 0.94 & $(0.06)$ \\
\hline
\end{tabular}

subjects were given a recognition test. It contained five old and five new slides; the new slides were pictures of architecturally similar areas.

The results can be seen in table 3 . In order to account for different guessing strategies, recognition scores for both visual and verbal recognition tests were calculated using the following correction formula: ((Number of correct responses) - (Number of incorrect responses))/(Number of items). ${ }^{29}$ Table 3 illustrates that the patients did well on the verbal recognition test; their scores are comparable to those of controls in the three delay conditions. Visual recognition was also comparable to that of controls. Recall was worse than recognition for both patients and controls (Wilcoxon Matched Pair Sample Test, $p<0.05$, for each patient and for the control group as a whole).

3 Assessment of responsiveness to retrieval cues: semantic cueing

Patients studied a list of twenty words that could be divided into four superordinate categories (five words within each category) and after a five minute delay, recalled what they remembered of the list. Following free recall, they were given the labels of the four categories, one label at a time, and asked to recall the previously studied examples. There were five trials. Data analysis compared free and cued recall.

The results can be seen in table 4 . Both patients and controls recalled more words when cued with the appropriate category than when left uncued. (Walsh test on each patient and control, $p<0.05$ ). Cued recall improved patients performance by almost three times the free recall performance rate.

\section{Assessment of susceptibility to interference}

Deficits in memory have been linked to increase interference from items that were to be remembered from a prior list..$^{30}{ }^{31}$ In this experiment, an analysis of the proportion of intrusions from other work lists can be used as a measure of interference effects. A rate of intrusions can be obtained

Table 4 Free and cued recall. Proportion correct (standard deviation)

\begin{tabular}{lllll}
\hline & \multicolumn{2}{l}{ Patients } & \multicolumn{2}{l}{$\begin{array}{l}\text { Control } \\
\text { group }\end{array}$} \\
\cline { 2 - 3 } & 1 & 2 & & \\
\hline Free recall & 0.19 & 0.08 & 0.51 & $(0.18)$ \\
Cued recall & 0.65 & 0.38 & 0.69 & $(0.16)$ \\
\hline
\end{tabular}

from the patients' performances in the free recall of verbal material. Ten free recall lists with ten words per list were administered with a few minutes delay between lists. Interest was in the number of correctly recalled words and the number correctly recalled that were from a list other than the particular to-be-remembered list. The results showed that the average number correct responses/list was 6.23 for controls and 2.45 for patients. The average total responses/list was 6.45 for the controls and 4.23 for the patients.

A measure of proactive interference was calculated by dividing the average of prior list intrusions by the average responses. This proportion for controls is around $1 \%$ (average prior list intrusions $=0.07$, average number of responses $=6.45$ ), and for a patient 1 is $14.4 \%$ (average prior list intrusion $=0.66$, average number of responses = 4.6 ), and for patient 2 in $38.5 \%$ (average prior list intrusion $=1 \cdot 5$, and average number of responses $=3 \cdot 9$ ). Prior list intrusions occurred more frequently for the patients than for controls. Even though the patients total number of responses was decreased, this measure of interference parallels their report of major difficulties distinguishing which of several responses to choose.

\section{Discussion}

In several respects, our patients were similar to other patients with amnesia after anterior communicating artery aneurysm rupture..$^{1218}$ Soon after surgery they were disoriented and confused; they could repeat digits, yet failed to remember events that had occurred since their accidents. One year later, their performamce on four experimental tasks was similar to the performance of amnesics in the chronic stable phase of alcoholic Korsakoff's amnesia. Free recall is severely depressed, recognition is less so, short term memory remains intact, semantic cues benefit recall, and proactive interference is more disruptive than it is for normals. However, our patients did not display other characteristics of Korsakoff's amnesia. They did not confabulate, they were oriented, and attentive; they could perform tasks that required sustained concentration.

The high recognition scores for our patients may be peculiar to this form of amnesia. For example, Talland $e t$ al. reported two patients with an amnesic syndrome after rupture of an anterior communicating artery aneurysm in whom some recognition ability was preserved. ${ }^{18}$ In fact one of Talland's patients showed improvement after the early stage of his illness to a level comparable to controls. On the other hand, the recognition ability for our patients may not be unique to patients with subarachnoid haemorrhage and aneurysm rupture. Recent studies have suggested that patients with alcoholic Korsakoff's amnesia recognise rare words better than they recall these items. ${ }^{32}$ In conditions of increased time for learning, Korsakoff's recognition perfor- 
mance rivalled controls. ${ }^{33}{ }^{34}$ Direct comparison of different amnesic groups on identical paradigms are necessary before any tentative conclusion regarding amnesics' recognition memory.

Our patients' amnesia also prompted a review of the pathophysiology of aneurysm rupture. Cerebral damage after anterior communicating artery aneurysm rupture or repair is caused by generalised vasospasm with ischaemia or infarction, ${ }^{1635}$ haemorrhage infarction into orbito-frontal lobes, ${ }^{101536}$ transtentorial herniation of the mesial temporal lobes, ${ }^{1536}$ or rapidly developing or late occurring communicating hydrocephalus. ${ }^{37}{ }^{38}$ There was no evidence that the patients in this report suffered any of these consequences of aneurysm rupture or repair except vasospasm. The precise mechanism of vasospasm is unclear, but the pathologic changes resulting from vasospasm have shown partial infarction and a range of ischaemic damage..$^{36}$ Characteristic microscopic analysis of areas of partial infarction after vasospasm show loss of most neuron cell bodies but preservation of supporting glia. Areas of profound ischaemia with spongy changes may also' appear. Vasospasm generally does not cause the complete destruction of cortex and white matter that are usually observed after infarction from arterial occlusion. ${ }^{36}$ It may be that vasospasm in our patients caused ischaemic changes that were beyond the limits of resolution of the CT scan. Whether these ischaemic changes occurred in focal cerebral areas like the orbital frontal lobes or the mesial temporal lobes may be investigated by measuring regional cerebral blood flow and metabolism. Recent studies of global cerebral blood flow and metabolism in patients with subarachnoid haemorrhage from aneurysm rupture suggested that vasospasm markedly depresses metabolism as well as blood flow, and increased the chances of ischaemic damage. ${ }^{39}$

The characterisation of the amnesia in our patients supports the observations of Tallard $e t$ al. that a chronic memory disorder can result from rupture and repair of an anterior cerebral artery aneurysm. ${ }^{18}$ It is not possible to judge whether preoperative vasospasm, or the surgical intervention caused the amnesic state in our patients. Other studies have shown that focal neurologic deficits associated with vasospasm do not have a rapid onset $t^{16174041}$ and in our patients the development of an amnesic syndrome 3 weeks after the ictus is consistent with these findings. It may be that focal neuropsychological deficits, as exemplified by the amnesic syndrome in our patients, are further late sequellae of vasospasm.

The authors acknowledge support from USPHS Grants NS 15572, and NS 17778, the Alfred P. Sloan Foundation and the Burke Foundation.

\section{References}

' Butters N, Cermak LS. Alcoholic Korsakoffs Syndrome: An Information-processing Approach to Amnesia. New York: Academic Press 1980.

${ }^{2}$ Victor M, Adams RD, Collins GH. The WernickeKorsakoff Syndrome. A clinical and pathological study of 245 patients, 82 with post-mortem examinations. Oxford: Blackwell 1971.

${ }^{3}$ Milner B, Penfield W. Amnesia following operation on the temporal lobes. In: Amnesia, Whitty CWM, Zangwill OL, eds. London: Butterworths 1966:10933.

${ }^{4}$ Scoville NB, Milner B. Loss of recent memory after bilateral hippocampal lesions. J Neurol Neurosurg Psychiatry 1957;20:11-21.

${ }^{5}$ Drachman DA, Adams RD. Acute herpes simplex and inclusion body encephalitis. Arch Neurol 1962;7:4560.

- Starr A, Phillips L. Verbal and motor memory in the amnestic syndrome. Neuropsychologia 1970;25:24 30.

${ }^{7}$ Nukui H, Miyagi O, Nojiri Ket al. Psychiatric symptoms in cases with ruptured anterior communicating aneurysm before and after surgery. Neurol Med Chir 1977;17:2, 335-41.

${ }^{8}$ Maeda S, Okawa M, Aiba T. Psychiatric symptoms of intracranial artery aneurysms: Pre- and post-surgical conditions and their follow-up observations. Clin Neurol 1974;14:1-9.

9 Sty HM, Nystrom ND. Psychodynamics in Subarachnoid Hemorrhage. Helsinki: TAS Kirjapaino Oy 1973.

${ }^{10}$ Luria AR. The Neuropsychology of Memory, Washington: Winston and Sons 1976:255-97.

${ }^{11}$ Norlen G, Olivacrona $H$. The treatment of aneurysms of the circle of Willis. J Neurosurg 1952;10:404-415.

${ }^{12}$ Lindquist G, Norlen G. Korsakoff's syndrome after operation on ruptured aneurysms of the anterior communicating artery. Act Psych Scand 1966;42:24 34.

${ }^{13}$ Sengupta RP, Chiu JSP, Brierly H. Quality of survival following direct surgery for anterior communicating artery aneurysms. J Neurosurg 1975;43:58-64.

${ }^{14}$ Logue V, Durward M, Pratt TRC et al. The quality of survival after rupture of an anterior cerebral aneurysm. Br J Psychiatry 1968;114:137-160.

${ }^{15}$ Hori S, Suzuki J. Early and late results of intracranial direct surgery of anterior communicating artery aneurysms. J Neurosurg 1979;50:433-40.

${ }^{16}$ Sakurai Y, Oka N, Suzuki J. Cerebral infarction due to vasospasm following intracranial aneurysm rupture. In: Cerebral Aneurysms Suzuki J, ed Japan. Tokyo: Neuron 1979;73-81.

${ }^{17}$ Saito I, Ueda Y, Sano K. Significance of vasospasm in the treatment of ruptured intracranial aneuryms. $J$ Neurosurg 1977;47:412-29.

${ }^{18}$ Talland GA, Sweet WH, Ballantine HT. Amnesic syndrome with anterior communicating artery aneurysm. J Nerv Ment Dis 1967;1452:179-92.

${ }^{19}$ Hunt WE. Grading of risk in intracranial aneurysms. In: Recent Progress in Neurological Surgery, Sano K, Ishii S, LeVay D, eds. Amsterdam: Excerpta Medica International Congress Series No. 320 1974:169-75. 
${ }^{20}$ Wechsler D. A standardized memory scale for clinical use. J Psychiatry 1945;19:87-95.

${ }^{21}$ Butters N, Albert MS. Process underlying failures to recall remote events. In: Human Memory and Amnesia. Hillsdale: Erlbaum Associates 1982.

${ }^{22}$ McEntee WJ, Mair RG. Memory impairment in Korsakoff's Psychosis: A correlation with brain noradrenergic activity. Science 1978;202:905-907.

${ }^{23}$ Lezak M. Neuropsychological Assessment. Oxford: Oxford University Press 1979.

${ }^{24}$ Milner B. Effects of different brain lesions on card sorting. Arch Neurol 1963;9:90-100.

${ }^{25}$ DeRenzi E, Vignolo LA. The token test: a sensitive test to detect disturbances in aphasics. Brain 1962;85:665-78.

${ }^{26}$ Hirst W. the amnesic syndrome: Descriptions and explanations. Psychol Bull 1982;91:435-460.

${ }^{27}$ Piercy MF. Experimental studies of the organic amnesic syndrome. In: Amnesia, 2nd ed. Edited by Whitty CWM, Zangwill OL, eds. London: Butterworths 1977.

${ }^{28}$ Rozin P. Psychobiological approach to human memory. In: Neural Mechanisms of Memory and Learning. Edited by Rosenzweig MR, Bennett EL, Cambridge: MIT Press 1976.

${ }^{29}$ Woodworth RS. Experimental Psychology. New York: Holt Reinhart and Winston 1938.

${ }^{30}$ Warrington EK, Weiskrantz L. New method of testing long term retention with special reference to amnesic patients. Nature 1968;217:972-4.

${ }^{31}$ Warrington EK, Weiskrantz L. A study of learning and retention in amnesic patients. Neuropsychologia 1968;6:283-92.

${ }^{32}$ Huppert FA, Piercy M. Recognition memory in amnesic patients: Effects of temporal context and familiarity of material. Cortex 1976;12:3-20.

${ }^{33}$ Huppert FA, Piercy M. Recognition memory in amnesia patients: A defect of acquisition? Neuropsychologia 1977;15:643-652.

${ }^{34}$ Huppert FA, Piercy M. In search of the functional locus of amnesic syndromes. In: Human Memory and Amnesia. Cermak LS, ed. Hillsdale: Erlbaum Associates 1982.

${ }^{35}$ Artiola I, Fortuny L, Adams CBT, Briggs M. Surgical mortality in an aneurysm population: Effects of age, blood pressure and preoperative neurological state. $J$ Neurol Neurosurg Psychiatry 1980;43:879-82.

${ }^{36}$ Hughes JT. Pathological changes associated with cerebral vasospasm. In Cerebral Vasospasm Bouillin DJ. ed. Chichester: Wiley 1980:171-206.

${ }^{37}$ Kodama T, Uemura S, Nonaka $\mathrm{N}$ et al. The quantitative analysis of psychiatric sequelae after direct surgery of anterior communicating aneurysms. Follow-up study. Neurol Med Chir 1977;17 (part 2), 327-333 (Japanese).

${ }^{38}$ Artiola I, Fortuny L, Prieto-Valiente L. Long term prognosis in surgically treated intracranial aneurysms. Part 1: Mortality. Part 2. Morbidity. J Neurosurg 1981;54:26-43.

${ }^{39}$ Grubb RL, Raichle ME, Eichling JO, Gado MH. Effects of subarachnoid hemorrhage on cerebral blood volume, blood flow, and oxygen utilization in humans. $J$ Neurosurg 1977;46:446-52.

${ }^{40-}$ Weir B, Grace M, Hansen J, Rothberg C. Time course of vasospasm in man. $J$ Neurosurg 1978;48:173-8.

${ }^{41}$ Mohan J. The neurosurgeon's view. In Cerebral Vasospasm, Edited by Bouillin DJ. Chichester: Wiley 1980:15-37. 